\title{
Evaluation of Shunt Losses in Industrial Silicon Solar Cells
}

\author{
P. Somasundaran and R. Gupta \\ Department of Energy Science and Engineering, Indian Institute of Technology Bombay, Powai, Mumbai 400076, India \\ Correspondence should be addressed to P. Somasundaran; somasundaran_kerala@iitb.ac.in
}

Received 11 April 2016; Accepted 6 June 2016

Academic Editor: Simona Binetti

Copyright (C) 2016 P. Somasundaran and R. Gupta. This is an open access article distributed under the Creative Commons Attribution License, which permits unrestricted use, distribution, and reproduction in any medium, provided the original work is properly cited.

\begin{abstract}
Shunting is one of the key issues in industrial silicon solar cells which degrade cell performance. This paper presents an approach for investigation of the performance degradation caused by the presence of ohmic extended shunts at various locations in industrial silicon solar cells. Location, nature, and area of the shunts existing in solar cells have been examined by lock-in infrared thermography (LIT). Based on LIT images and experimental dark $I-V$ curves of solar cell, shunted cell has been modeled, from which loss in fill factor and efficiency due to the specific shunt has been obtained. Distributed diode modeling approach of solar cell has been exploited for obtaining simulation results which were supported by experimental measurements. The presented approach is useful to estimate performance reduction due to specific shunts and to quantify losses, which can help in improving the efficiency of solar cell during production by tackling the shunt related problems based on the level of severity and tolerance.
\end{abstract}

\section{Introduction}

Many types of defects are present in solar cells which affect its performance [1]. Among them, shunt is one of the critical defects which can degrade performance of solar cells drastically. Information related to quantum of power losses due to the presence of shunts in industrial silicon solar cells can play an important role in process control and improvement of solar cell production.

Shunts can broadly be classified into two broad categories based on the origin: process induced shunts and material related shunts [2]. Process induced shunts are formed during the production due to problems associated with fabrication process. These types of shunts can be minimized by better process control, monitoring tool, and handling. Some typical process related shunts formation happens due to cracks in wafer, scratches, improper metallization contact, aluminium particles, and so forth, whereas material related shunts are mainly impurities like macroscopic $\mathrm{Si}_{3} \mathrm{~N}_{4}$ inclusions, $\mathrm{SiC}$ particles, and $\mathrm{SiC}$ filament-type precipitates [2]. These can be minimized by using better quality of material which will increase cost of the cell. Physical nature of dominant material induced shunts has been experimentally investigated and its qualitative effects on specific location have been discussed earlier $[3,4]$.
Quantum of loss due to shunts on the overall solar cell performance depends not only on the severity of shunt but also on its location. It is important to know the quantum of losses due to shunts in order to prioritize the solution of shunting problem according to severity of shunts. It will be very useful and relevant to industry in classifying the shunts in different categories based on the level of severity in order to tackle the shunting problem during production. Shunts which cause more reduction in output power may be removed or isolated using laser technique $[5,6]$ and leaving out those shunts which cause relatively low loss in efficiency of the cell. Also, corrective steps in production can be taken up based on severity of shunts in order to remove the origin of these process induced shunts.

In order to study the quantum of loss due to shunts in industrial silicon solar cell, a combined experimental and simulation based approach has been presented in this paper. The presented approach is based on the distributed diode model of solar cell, experimental characteristics, and shunt imaging technique.

Solar cell simulation based on distributed diode model is well known and it has been reported for studying different type of effects on solar cell and module [7-12].

In the present work, experimental parameters have been incorporated in simulation to study the losses due to shunts at 
various locations on industrial solar cell. A refined approach for extended shunts has been presented. The proposed approach has been supported with actual experimental results.

\section{Approach and Methodology}

In order to model and analyze the performance of solar cell in the presence of shunts and to study losses induced by these shunts in industrial silicon solar cell, a distributed diode model of solar cell has been developed from the electrical equivalent circuit of illuminated solar cell, consisting of single diode in parallel with current source and shunt resistance, with a series resistance. An electrical circuit simulator PSpice [13] has been used to simulate this model. Some parameters for this simulation have been obtained experimentally from dark $I-V$ characteristic of solar cells and shunt imaging technique.

Lock-in infrared thermography (LIT) has been exploited for imaging the shunt location and to study the relative severity of shunt [14]. Nature, location, relative severity, and area of shunts have been obtained in solar cells by this technique.

Some parameters (shunt resistance, reverse saturation current, ideality factor, sheet resistivity, etc.) which were required for distributed diode model have been obtained experimentally in order to simulate the $I-V$ characteristic of shunt-free cell. The simulated and experimental dark $I-V$ characteristic of the shunt-free solar cell has been compared to support the model and simulation. Based on this model and simulation as well as LIT images, shunt losses in quantitative terms have been estimated.

The basic methodology of proposed approach for simulation by PSpice is described in Figure 1. Shunting can happen in very small point in the solar cell, and therefore it is necessary to divide the given cell area into a large number of elementary areas, in order to represent each small region of the solar cell in the model. All industrial silicon cells in the present work have an area of $125 \mathrm{~mm} \times 125 \mathrm{~mm}$. For simulation, the cell was divided into $375 \times 375$ sections in order to accommodate finger size of solar cells. Figure 2 shows how the cell area has been divided into equal elementary areas.

Each elementary area was modeled by solar cell equivalent circuit consisting of a diode, a shunt resistance, and a current source in parallel as shown in Figure 3. Resistances were connected between neighboring elementary areas taking into account the emitter sheet resistance of the cell. The base resistance of cell has been neglected since its value is very small compared to the sheet resistance of top $n$ layer. Fingers and bus bars of the cell have been modeled after measuring respective resistances.

Ideality factor $n$, reverse saturation current $I_{o}$, series resistance $R_{s}$, and photo-generated current $I_{L}$ for each cell under study has been calculated by the analytical method proposed in $[15,16]$, from the manufacturer's data sheet and the experimental dark $I-V$ curves:

$$
\begin{aligned}
n & =\frac{\left[V_{m}+R_{\mathrm{so}} I_{m}-V_{\mathrm{oc}}\right]}{\left[V_{\mathrm{th}}\left\{\ln \left(I_{\mathrm{sc}}-V_{m} / R_{\mathrm{sho}}-I_{m}\right)-\ln \left(I_{\mathrm{sc}}-V_{\mathrm{oc}} / R_{\mathrm{sh}}\right)+I_{m} /\left(I_{\mathrm{sc}}-\left\{V_{\mathrm{oc}} / R_{\mathrm{sho}}\right\}\right)\right\}\right]}, \\
I_{o} & =\left(I_{\mathrm{sc}}-\frac{V_{\mathrm{oc}}}{R_{\mathrm{sh}}}\right) \exp \left(-\frac{V_{\mathrm{oc}}}{n V_{\mathrm{th}}}\right), \\
R_{s} & =R_{\mathrm{so}}-\left(\frac{n V_{\mathrm{th}}}{I_{o}}\right) \exp \left(-\frac{V_{\mathrm{oc}}}{n V_{\mathrm{th}}}\right), \\
I_{L} & =I_{\mathrm{sc}}\left(1+\frac{R_{\mathrm{s}}}{R_{\mathrm{sh}}}\right)+I_{o}\left\{\exp \left(\frac{I_{\mathrm{sc}} R_{s}}{n V_{\mathrm{th}}}\right)-1\right\},
\end{aligned}
$$

where $V_{m}$ is the voltage at MPP (V), $R_{\text {so }}$ is the reciprocal of slope of $I-V$ curve at open circuit point $(\Omega), I_{m}$ is the current at MPP (A), $V_{\text {oc }}$ is the open circuit voltage $(\mathrm{V}), V_{\text {th }}$ is thermal voltage $=k T / q$ at $300 \mathrm{~K}(\mathrm{~V}), I_{\mathrm{sc}}$ is the short circuit current (A), $R_{\text {sho }}$ is the reciprocal of slope of $I-V$ curve at short circuit point $(\Omega), I_{\mathrm{sc}}$ is the short circuit current $(\mathrm{A})$, and $R_{\mathrm{sh}}$ is the shunt resistance $(\Omega)$. The values of $I_{o}$ and $n$ have been averaged over number of samples and used in distributed diode model to represent shunt-free region diodes values of $I_{o}$ and $n$. Main parameters of the five shunted cells $(1,2,3$, 4 , and 5) and four cells having no shunts (A, B, C, and D) have been summarized in Tables 1 and 2. Values of $I_{o}, n$, and $R_{s}$ calculated based on the analytical method are listed in Table 3.
Current flow in the model can be described based on the Shockley's diode equation:

$$
\begin{aligned}
I= & I_{L}-\frac{\left(V+I R_{s}\right)}{R_{\mathrm{sh}}} \\
& -I_{o}\left[\exp \left\{\left(\frac{q}{n k T}\right)\left(V+I R_{s}\right)\right\}-1\right],
\end{aligned}
$$

where $I_{L}$ is the photo-generated current (A), $I$ the net current flowing through the cell (A), $I_{o}$ reverse saturation current (A), $q$ electronic charge (C), $V$ applied voltage across terminals of cell (V), $n$ ideality factor, $k$ Boltzmann's constant $(\mathrm{J} / \mathrm{K})$, and $T$ absolute temperature $(\mathrm{K}) . R_{s}$ is the series resistance $(\Omega)$ and $R_{\text {sh }}$ is the shunt resistance $(\Omega)$. 
TABLE 1: Main parameters of analyzed shunted cells under 1-sun irradiance.

\begin{tabular}{lccccc}
\hline Cell & Open circuit voltage [V] & Short circuit current [A] & Efficiency [\%] & Fill factor [\%] & Shunt resistance [ $\Omega$ ] \\
\hline 1 & 0.619 & 4.93 & 14.93 & 76.45 & 3.37 \\
2 & 0.612 & 4.91 & 14.42 & 74.97 & 2.22 \\
3 & 0.613 & 4.95 & 14.58 & 75.04 & 1.94 \\
4 & 0.617 & 5.18 & 15.89 & 77.70 & 5.02 \\
5 & 0.614 & 5.18 & 15.34 & 75.35 & 2.64 \\
\hline
\end{tabular}

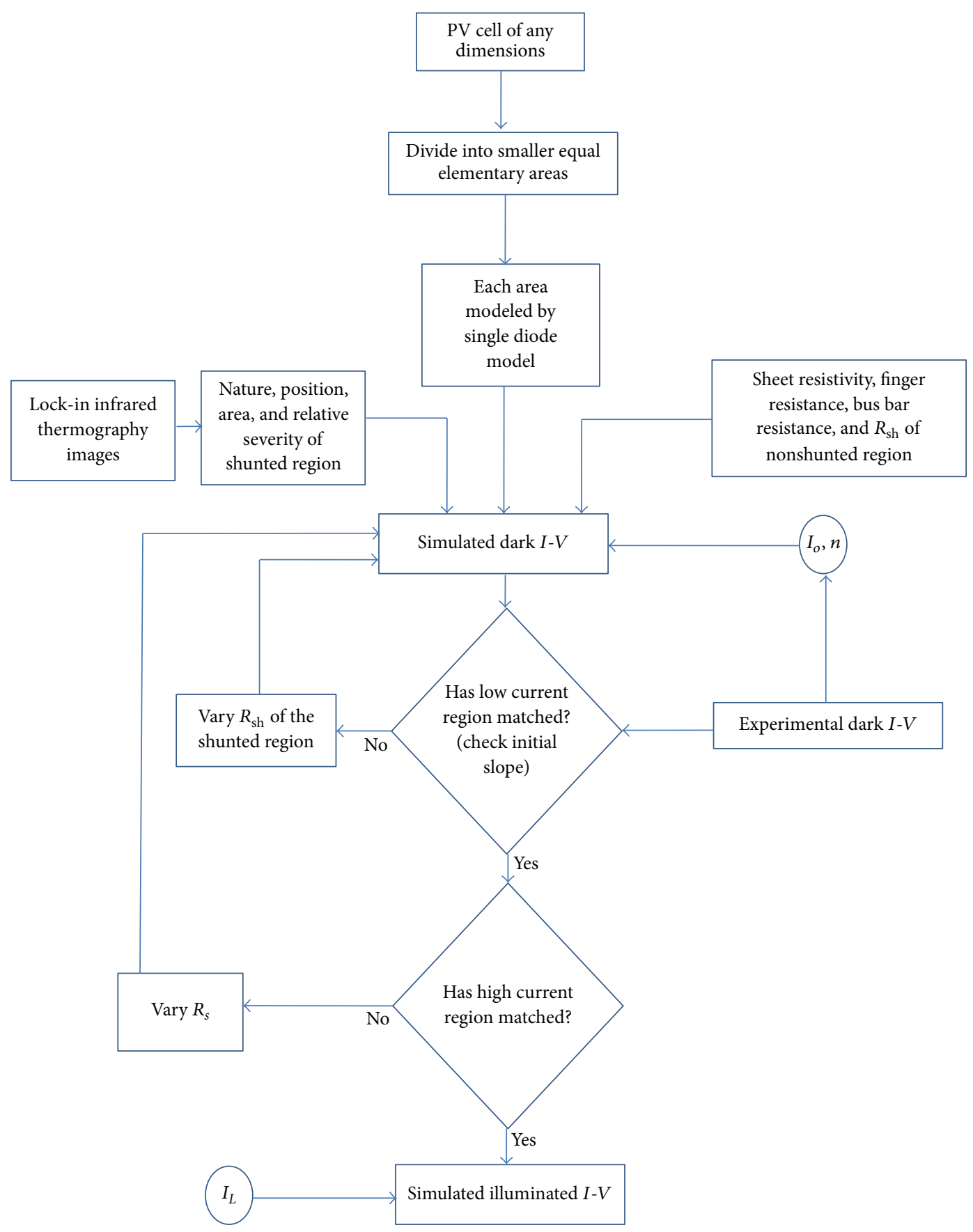

FIGURE 1: Flow chat describing the methodology adopted for the proposed simulation. 
TABLE 2: Main parameters of analyzed cells having no shunts under 1-sun irradiance.

\begin{tabular}{lccccc}
\hline Cell & Open circuit voltage [V] & Short circuit current [A] & Efficiency [\%] & Fill factor [\%] & Shunt resistance [ $\Omega$ ] \\
\hline A & 0.621 & 5.10 & 15.81 & 77.98 & 30.08 \\
B & 0.619 & 5.11 & 15.92 & 78.58 & 16.16 \\
C & 0.613 & 5.15 & 16.67 & 78.30 & 150 \\
D & 0.614 & 5.17 & 16.78 & 78.40 & 150 \\
\hline
\end{tabular}

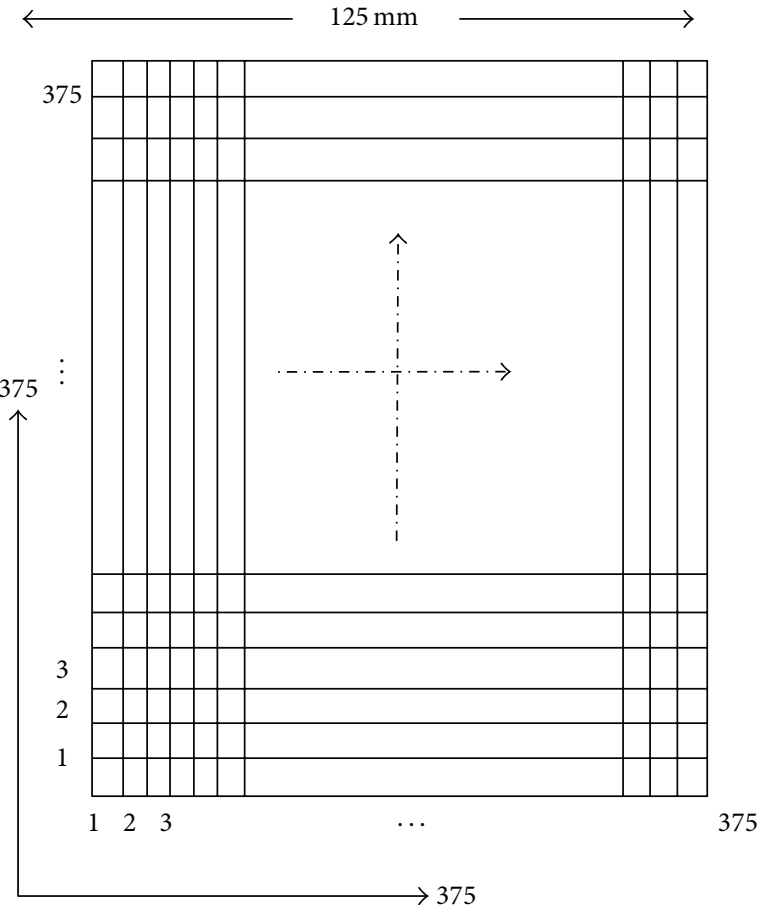

FIGURE 2: Division of the solar cell into $375 \times 375$ equal elementary areas.

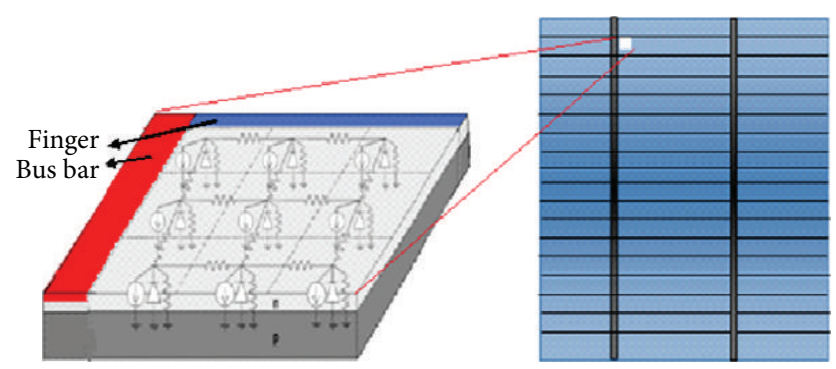

FIGURE 3: Distributed diode model showing only $3 \times 3$ sections in the white square on the right.

In the dark condition, the equation reduces to the following form:

$$
I=I_{o}\left[\exp \left(\frac{q V}{n k T}\right)-1\right] .
$$

In a solar cell, at very low voltages under forward bias conditions, a very minimal current flows through the cell which is predominantly controlled by shunt resistance $\left(R_{\mathrm{sh}}\right)$
TABLE 3: Parameters extracted from the experimental dark $I-V$ curves and manufacturer's data sheet by analytical method for the nonshunted cells (A, B, C, and D) and shunted cells (1, 2, 3, 4, and 5) considered for study.

\begin{tabular}{lcccc}
\hline Cell & $I_{o}[\mathrm{~A}]$ & $n$ & $R_{\mathrm{sh}}[\Omega]$ & $R_{s}[\Omega]$ \\
\hline $\mathrm{A}$ & $5.79 E-09$ & 1.17 & 32.95 & 0.014 \\
$\mathrm{~B}$ & $3.48 E-09$ & 1.13 & 18.64 & 0.009 \\
$\mathrm{C}$ & $3.08 E-07$ & 1.43 & 149.11 & 0.019 \\
$\mathrm{D}$ & $2.22 E-09$ & 1.1 & 156.55 & 0.005 \\
1 & $1.48 E-08$ & 1.22 & 4.3 & 0.017 \\
2 & $6.47 E-09$ & 1.16 & 3.7 & 0.011 \\
3 & $8.37 E-08$ & 1.33 & 4.1 & 0.018 \\
4 & $6.19 E-09$ & 1.16 & 6.42 & 0.014 \\
5 & $4.04 E-09$ & 1.14 & 2.85 & 0.005 \\
\hline
\end{tabular}

[17] of the cell. Shunt resistance $\left(R_{\mathrm{sh}}\right)$ of cell has been experimentally measured at extremely low voltage from the slope of $I-V$ curve under dark condition. This measurement was performed on a number of shunt-free cells after verification by LIT measurements. Shunt-free cell was taken from the same batch where shunted cells have been taken for this entire study.

For a shunt-free cell, shunt resistance of each elementary area has been estimated by considering the uniform distribution of overall shunt resistance over the cell $R_{\mathrm{sh}}$. The same elementary shunt resistance value has been used in shunt-free region of shunted cell during simulation.

Lock-in thermography has been used over the cells for finding relative severity, area, location, and nature of shunts in the cell. These measurements have been performed at high lock-in frequency, in order to obtain fine spatial resolution of the shunted region.

Shunt resistance at shunted positions has been obtained by matching initial slope of simulated dark $I-V$ curve with experimental dark $I-V$ curve at very low voltage. Also, relative strength of the LIT signal over the shunts has been considered in this matching.

Full dark $I-V$ curve of the cell has been simulated by using the measured average sheet resistivity value of cells along with other parameters obtained earlier. Similarly, illuminated $I-V$ curve of solar cell has been simulated by modeling incident radiation as a current source in distributed diode model.

Sheet resistance value of the same batch of cells has been measured on number of cells at different locations. The average value of sheet resistance has been used in simulation to obtain the full dark $I-V$ curve of the cell. The sheet resistance value was kept the same everywhere in the network. For 


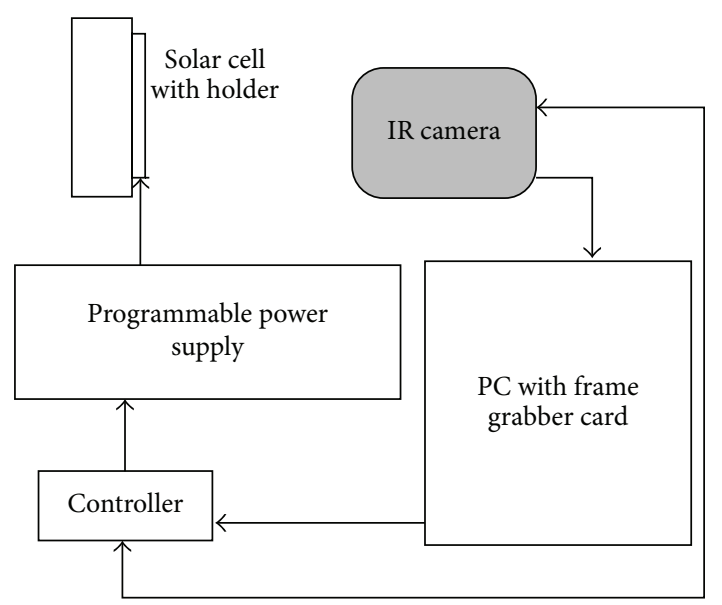

FIgURE 4: Experimental setup to carry out dark lock-in infrared thermography.

obtaining the dark $I-V$ characteristics, varying voltage was applied across the $p$ and $n$ side. For obtaining the illuminated $I-V$ curves, a current source capable of generating a current equal to the short circuit current (normalized according to the area of the elementary region) has been connected in parallel with each diode in the network to model uniform incident radiation under standard illumination conditions.

\section{Experimental}

The present work is based on the characterization of several monocrystalline and multicrystalline solar cells. In the following, the results obtained on five representative samples featuring shunts of different position, area, and severity have been reported. The main electrical parameters of these five cells are reported in Table 1. Two types of measurements have been made: (1) thermographic characterization and (2) dark $I-V$ characterization.

3.1. Thermographic Characterization. The dark LIT (DLIT) technique has been used for finding location, severity, nature, and area of shunt. In this technique, cell is periodically biased under dark condition with a programmable power supply in order to localize the generated heat near to the shunted region. Under this condition only dark current will flow through the cell. At shunt sites, an increased current causes heating of the solar cell which can be detected by DLIT technique [18]. Infrared camera, which is synchronized with power supply, takes sequence of images and applies lockin algorithm over the images in order to detect very small temperature change over the shunted region.

The schematic block diagram of DLIT measurement system is shown in Figure 4. The system is equipped with an FLIR camera having cooled detector with focal plane array $(320 \times 256)$ of IR sensors. The camera is sensitive in 3$5 \mu \mathrm{m}$ wavelength and it can work at maximum frame rate of $160 \mathrm{~Hz}$. Programmable DC power supply in this system was used for biasing the solar cells, which was synchronized with the camera frame through a controller to implement lockin algorithm over the captured images. Relative intensity of DLIT signal over the shunts gives relative estimation of shunt severity. Other than finding the location, severity, and area of shunts, DLIT has been used to classify the ohmic (linear) and nonohmic (nonlinear) nature of shunts. Ohmic shunts give the same signal value under forward and reverse biasing condition where nonohmic shunts give different value. It has been observed that most of the shunts were ohmic in nature and present study is focused on ohmic shunts.

In reverse bias conditions, only small leakage current flows through the cell which makes ohmic shunts detection much easier. Also estimation of shunt area in reverse direction under high lock-in frequency is more appropriate.

In this study, five silicon solar cells (designated as 1, 2, 3, 4, and 5) have been used, which had different shunt resistances. Out of these, cells 1, 2, and 3 were monocrystalline cells and remaining cells were multicrystalline cells. DLIT has been performed on all these cells. Different types of shunts were observed in these cells.

Figure 5 shows the DLIT images of all the five cells. Figure 5(a)1 shows the DLIT image of monocrystalline cell 1 taken in forward bias. The shunt appeared in reverse bias also with equal intensity and area, which is seen in Figure 5(b)1, which shows that it is ohmic in nature. It was located between the two bus bars, but more towards the left bus bar. In order to get more information of shunt for simulation, the shunted region has been imaged more precisely by using the zoom lens of the camera. The zoom image (Figure 5(c)1) reveals that the shunt extends below several fingers.

DLIT images of monocrystalline cells 2 and 3 shown in Figures 5(a)2-5(c)2 and 5(a)3-5(c)3 revealed very interesting ohmic shunts in the close proximity of the metallization, which can possibly lead to considerable performance loss. The zoom images of the shunted region in the cells have been taken to estimate the area and location of shunted region. The DLIT forward bias image of cell 3 reveals a nonlinear or nonohmic shunt, which is indicated by a circle in Figure 5(a)3.

DLIT image of the multicrystalline cells 4 and 5 shown in Figures 5(a)4-5(c)4 and 5(a)5-5(c)5 indicated the presence of ohmic shunts of extended area near the edge of the two cells. The close view images of the shunted regions have indicated that both the shunts originate from an extended region along the edge.

3.2. Dark I-V Characterization. The experimental dark I$V$ curve of both the shunted and shunt-free cells used for investigation has been measured by the experimental setup in the laboratory. The experimental dark $I-V$ curves contain information about lumped values of the parameters such as the ideality factor, reverse saturation current, series resistance, and shunt resistance with respect to the total area of the solar cell. Additional parameters required for the model formulation are the bus bar and finger resistances as well as the sheet resistivity. The bus bar resistance, finger resistance, and sheet resistivity for each shunted and nonshunted cell have been measured by the four-probe setup in the laboratory. 

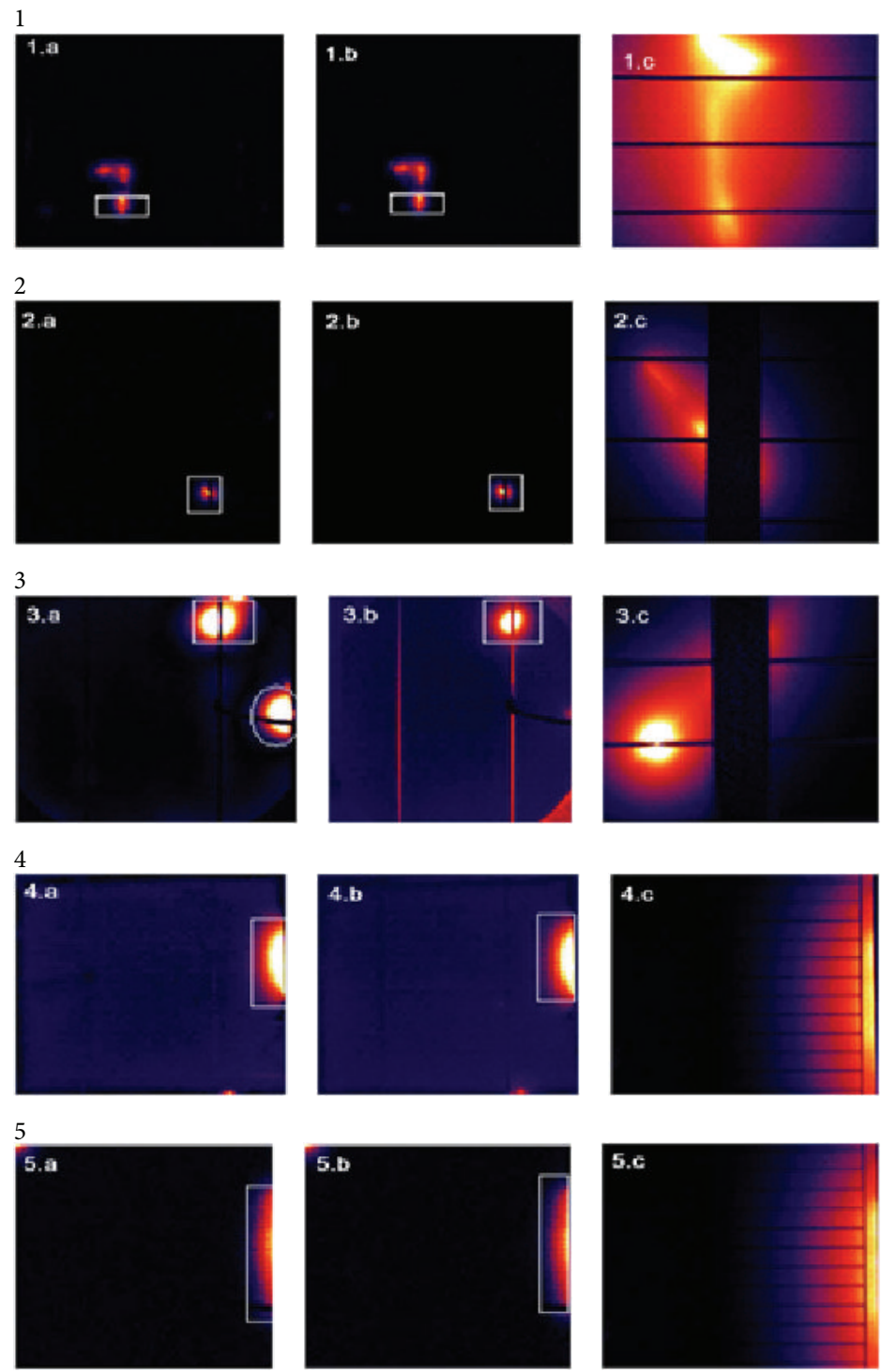

(a)

(b)

(c)

Figure 5: DLIT images of monocrystalline cells 1, 2, and 3 and the multicrystalline cells 4 and 5 measured in forward (a) and reverse bias (b). Zoom image of the part of shunted area enclosed in rectangle is the third image (c).

Figure 6 presents the comparison of experimental and simulated dark $I-V$ curves of monocrystalline cell $\mathrm{A}$ and multicrystalline cell $\mathrm{C}$ having no shunts. There is a good degree of agreement in the case of cell $\mathrm{A}$ in the critical regions of the curves. It can be seen from Figure 6 that, in the case of cell $\mathrm{C}$, there is a deviation between the experimental and simulated curves which can be possibly due to a dominant junction recombination mechanism in the solar cell or due to variation in the solar cell characteristic parameters over the entire cell area.

\section{Results and Discussion}

Shunted monocrystalline cell 1 and cell 2, whose DLIT images are shown in Figures 5(a)1-5(c)1 and 5(a)2-5(c)2, have been simulated, considering location, area, and severity of the shunted region. Resulting simulated dark $I-V$ curves are compared with experimental dark $I-V$ curves in Figure 7. Comparison of experimental and simulated dark $I-V$ curves for the shunted multicrystalline cells 4 and 5 can be seen in Figure 8 . The deviation in a few regions between the experimental and simulated curves in Figures 7 and 8 can be attributed to the inhomogeneity in the solar cell characteristic parameters over the entire solar cell area, whereas in the presented model a homogeneous distribution of the solar cell characteristic parameters has been assumed.

Degradation in efficiency and fill factor has been found from illuminated $I-V$ curve of the shunted cell and that of the corresponding shunt-free cell evaluated by replacing the shunted region determined using DLIT image by the 
TABLE 4: Summary of efficiency, fill factor, and cell shunt resistance values for shunted (experimental and simulated) and the shunt-free (simulated) cases of cells 1, 2, 3, 4, and 5 .

\begin{tabular}{|c|c|c|c|c|}
\hline Cell & Case & Efficiency (\%) & Fill factor (\%) & Cell shunt resistance $(\Omega)$ \\
\hline \multirow{3}{*}{1} & Experimental & 14.96 & 76.45 & 3.37 \\
\hline & Simulated & 14.93 & 76.44 & 3.37 \\
\hline & If not shunted & 15.80 & 78.65 & 31.36 \\
\hline \multirow{3}{*}{2} & Experimental & 14.42 & 74.97 & 2.22 \\
\hline & Simulated & 14.41 & 74.93 & 2.22 \\
\hline & If not shunted & 15.92 & 79.14 & 27.29 \\
\hline \multirow{3}{*}{3} & Experimental & 14.58 & 75.04 & 1.94 \\
\hline & Simulated & 14.56 & 75.01 & 1.94 \\
\hline & If not shunted & 15.54 & 78.05 & 19.76 \\
\hline \multirow{3}{*}{4} & Experimental & 16.74 & 77.7 & 5.02 \\
\hline & Simulated & 16.71 & 77.62 & 5.02 \\
\hline & If not shunted & 16.97 & 78.64 & 19.77 \\
\hline \multirow{3}{*}{5} & Experimental & 16.15 & 75.35 & 2.64 \\
\hline & Simulated & 16.14 & 75.33 & 2.64 \\
\hline & If not shunted & 16.65 & 77.36 & 63.59 \\
\hline
\end{tabular}

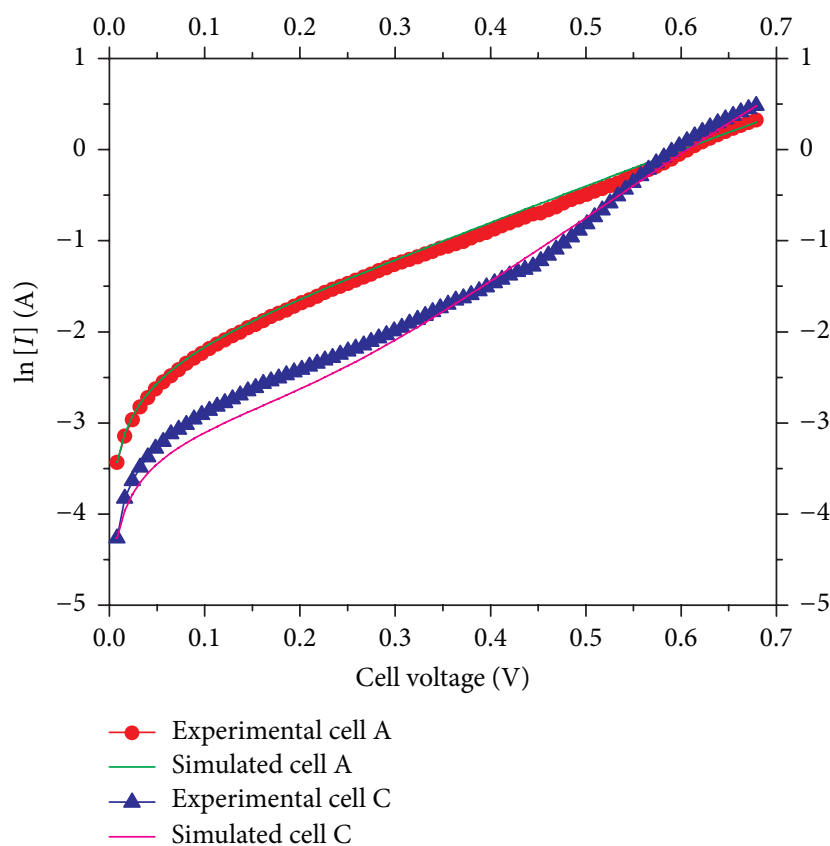

Figure 6: Comparison of experimental and simulated dark $I-V$ curves for monocrystalline cell A and multicrystalline cell C, having no shunts.

shunt-free region in the distributed diode model of the shunted cell. Similarly, simulated illuminated $I-V$ curves of shunted and not shunted cases for each cell have been found in order to determine degradation in electrical performance.

Table 4 summarizes the results of investigation on degradation caused by shunts on the five cells found using the model. Experimentally measured values of fill factor and efficiency have been provided to verify the accuracy of the model and they closely match with the simulated values.

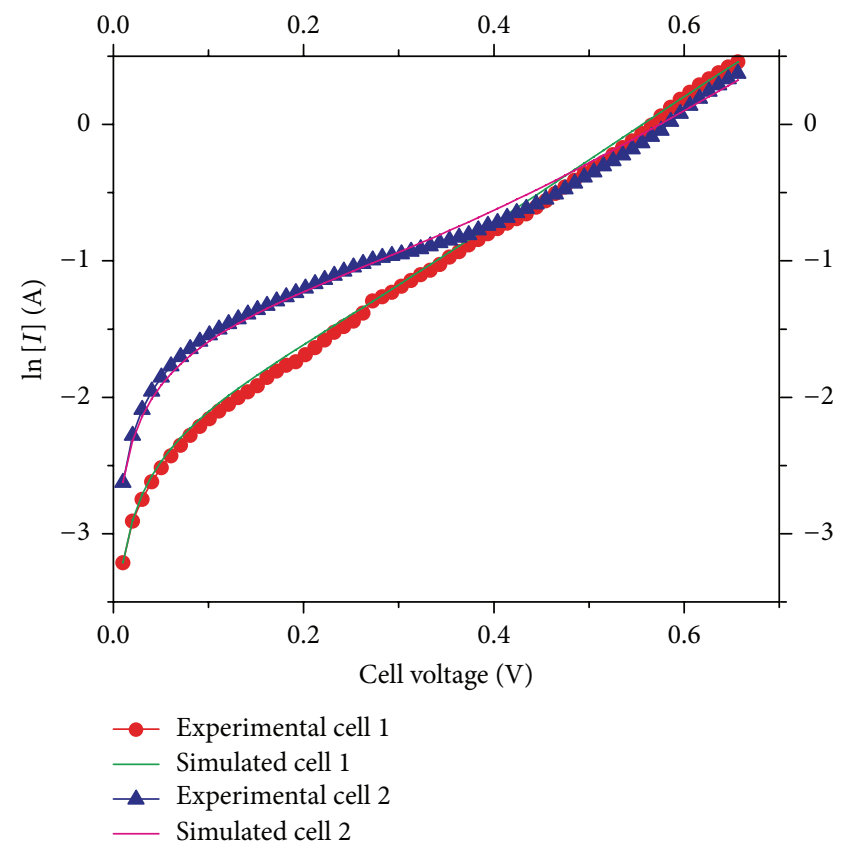

FIGURE 7: Comparison of the experimental and simulated dark $I-V$ curves for shunted monocrystalline cells 1 and 2 .

It is clear from Table 4 that the absolute degradation in efficiency and fill factor of all the five cells depends to a great extent on the shunt resistance and hence on the severity, area, location, and nature of shunts present in the cell. Since the shunt in cell 2 is under the bus bar, more degradation has occurred in cell 2, though comparatively greater area between two bus bars is affected by shunting in cell 1 . For cell 2, degradation in efficiency of $1.51 \%$ and degradation in fill factor $4.21 \%$, respectively, have been observed. The results prove that efficiency improvement of approximately 1 to $1.5 \%$ and fill factor improvement from 3 to $4 \%$ are possible by 


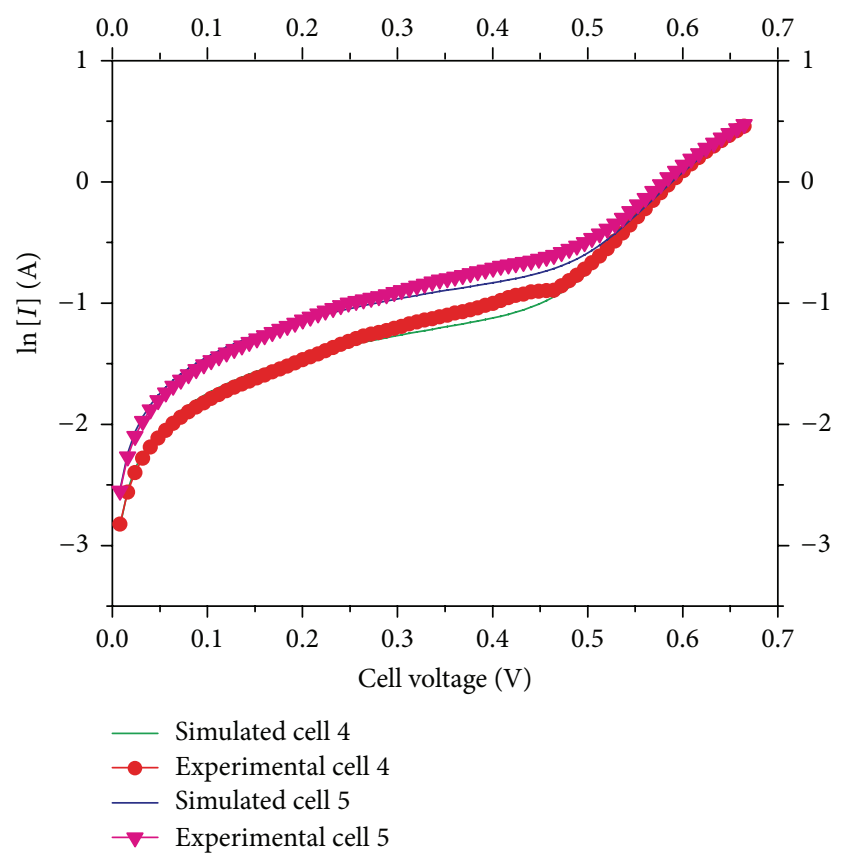

FIGURE 8: Comparison of the experimental and simulated dark $I-V$ curves for shunted multicrystalline cells 4 and 5 .

avoiding severe shunt formation or isolating them by laser technique [6] in silicon solar cells. This is particularly true when shunted area is under the bus bar and also if many metallization fingers are affected by shunt. The reason is simply that the bus bar carries the greatest current compared to other areas and hence more current is available to sink through the shunt path, lowering the output current.

\section{Conclusions}

A simple approach based on DLIT images, experimental dark $I-V$ curves, and distributed diode model has been presented to characterize the shunt losses in industrial solar cells. Based on the five samples investigated, it can be inferred that improvement in efficiency in the range of $1 \%$ to $1.5 \%$ and improvement in fill factor of 3 to $4 \%$ can be possible by avoiding the severe shunt formation in production line by taking corrective measures.

The loss in fill factor and efficiency will vary depending on the exact area and severity of the extended shunt. Value of sheet resistivity will affect the cell shunt resistance when shunts are not under metallization and hence the fill factor and efficiency are affected. Presented approach is useful to improve the efficiency and fill factor of the solar cell in the production line by tackling the shunts related problems based on the level of severity and tolerance and to take corrective measures in the production process or in the material manufacturing industry depending upon the relative loss in efficiency and fill factor caused by the presence of shunts at different spatial locations of the cell. Since the LIT technique can detect strong shunts in a few seconds [19], the presented approach can be implemented very fast.

\section{Competing Interests}

The authors declare that they have no competing interests.

\section{References}

[1] O. S. Sastry, V. Dutta, A. K. Mukerjee, and K. L. Chopra, "Defect analysis in polycrystalline silicon solar cells," Journal of Applied Physics, vol. 57, no. 12, pp. 5506-5511, 1985.

[2] O. Breitenstein, J. P. Rakotoniaina, M. H. Al Rifai, and M. Werner, "Shunt types in crystalline silicon solar cells," Progress in Photovoltaics: Research and Applications, vol. 12, no. 7, pp. 529-538, 2004.

[3] O. Breitenstein, J. Bauer, and J. P. Rakotoniaina, "Materialinduced shunts in multicrystalline silicon solar cells," Semiconductors, vol. 41, no. 4, pp. 440-443, 2007.

[4] M. Kasemann, D. Grote, B. Walter et al., "Luminescence imaging for the detection of shunts on silicon solar cells," Progress in Photovoltaics: Research and Applications, vol. 16, no. 4, pp. 297-305, 2008.

[5] L. Zhang, H. Shen, Z. Yang, and J. Jin, "Shunt removal and patching for crystalline silicon solar cells using infrared imaging and laser cutting," Progress in Photovoltaics: Research and Applications, vol. 18, no. 1, pp. 54-60, 2010.

[6] M. D. Abbott, T. Trupke, H. P. Hartmann, R. Gupta, and O. Breitenstein, "Laser isolation of shunted regions in industrial solar cells," Progress in Photovoltaics: Research and Applications, vol. 15, no. 7, pp. 613-620, 2007.

[7] A. Zekry and A. Y. Al-Mazroo, "A distributed SPICE-model of a solar cell," IEEE Transactions on Electron Devices, vol. 43, no. 5, pp. 691-700, 1996.

[8] S. E. Foss, B. R. Olaisen, E. S. Marstein, and A. Holt, "A new 2.5 D distributed SPICE model of solar cells," in Proceedings of the 21st European Photovoltaic Solar Energy Conference, pp. 430434, Dresden, Germany, 2006.

[9] B. Galiana, C. Algora, I. Rey-Stolle, and I. García Vara, "A 3-D model for concentrator solar cells based on distributed circuit units," IEEE Transactions on Electron Devices, vol. 52, no. 12, pp. 2552-2558, 2005.

[10] R. Gupta, P. Somasundaran, and D. K. Nandi, "Electrical simulation and characterization of shunts in solar cells," Applied Mechanics and Materials, vol. 110-116, pp. 2453-2457, 2012.

[11] P. Somasundaran, A. Sinha, and R. Gupta, "Simulation and characterization of spatial variation of shunts in industrial solar cells by PSpice and dark lock-in infrared thermography," in Proceedings of the 27th European Photovoltaic Solar Energy Conference and Exhibition, Frankfurt, Germany, September 2012.

[12] R. Gupta, O. Breitenstein, and J. Schneider, "Characterization of crystalline silicon on glass (CSG) modules by surface potential mapping," in Proceedings of the 22nd European Photovoltaic Solar Energy Conference, pp. 1434-1437, Milan, Italy, 2007.

[13] Cadence Design System, OrCAD PSPICE Release 16.2, 2009.

[14] R. Gupta and O. Breitenstein, "Unsteady-state lockin thermography-application to shunts in solar cells," Quantitative InfraRed Thermography Journal, vol. 4, no. 1, pp. 85-105, 2007.

[15] J. C. H. Phang, D. S. H. Chan, and J. R. Phillips, "Accurate analytical method for the extraction of solar cell model parameters," Electronics Letters, vol. 20, no. 10, pp. 406-408, 1984. 
[16] A. M. Humada, M. Hojabri, S. Mekhilef, and H. M. Hamada, "Solar cell parameters extraction based on single and doublediode models: a review," Renewable and Sustainable Energy Reviews, vol. 56, pp. 494-509, 2016.

[17] J. Salinger, "Measurement of solar cell parameters with dark forward I-V characteristics," Acta Polytechnica, vol. 46, pp. 2527, 2006.

[18] O. Breitenstein, W. Warta, and M. Langenkamp, Lock-in Thermography: Basics and Use for Evaluating Electronic Devices and Materials, Springer, Berlin, Germany, 2010.

[19] R. Gupta, O. Breitenstein, J. Zettner, and D. Karg, "In-line shunt detection in solar cells by fast lock-in infrared thermography," in Proceedings of the 22nd European Photovoltaic Solar Energy Conference, pp. 1975-1978, Milan, Italy, September 2007. 

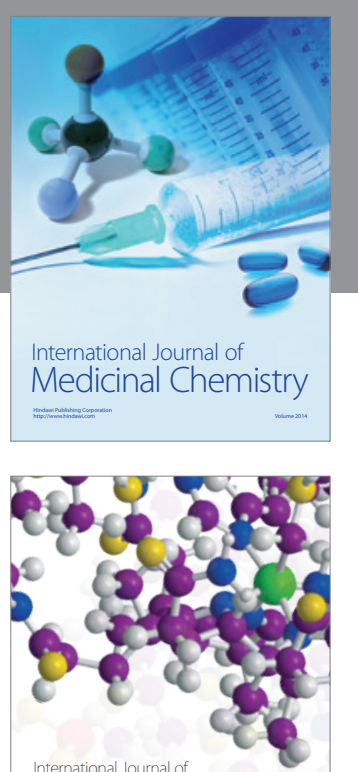

Carbohydrate Chemistry

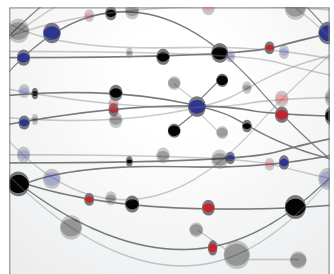

The Scientific World Journal
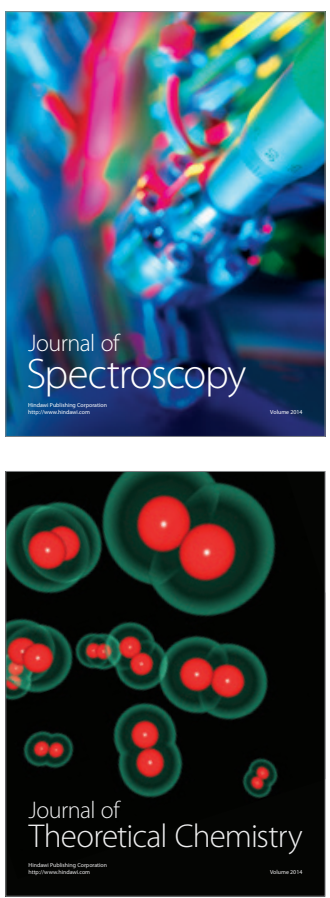
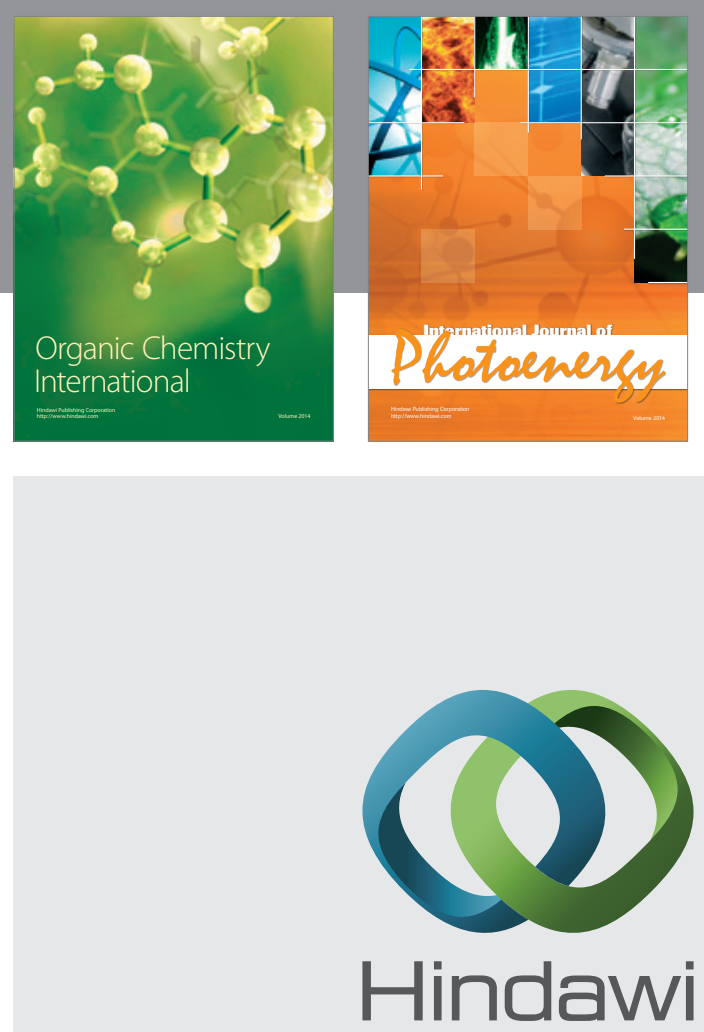

Submit your manuscripts at

http://www.hindawi.com

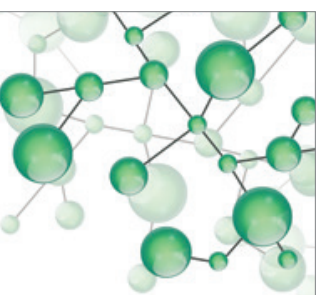

International Journal of

Inorganic Chemistry

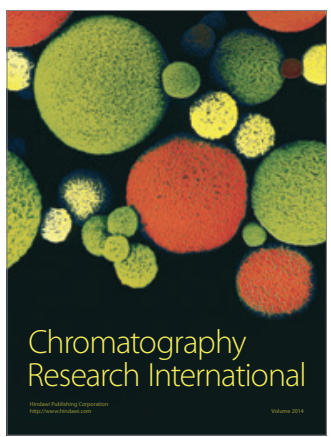

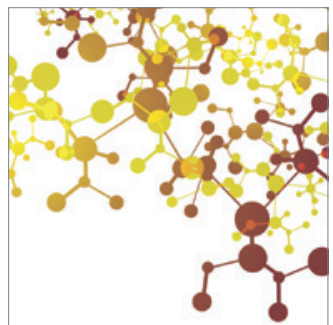

Applied Chemistry
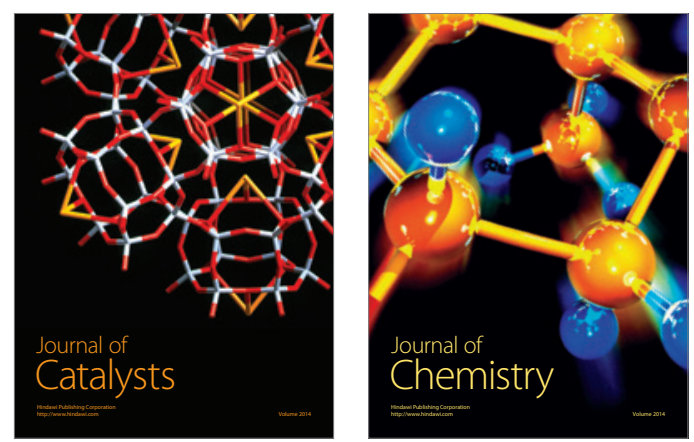
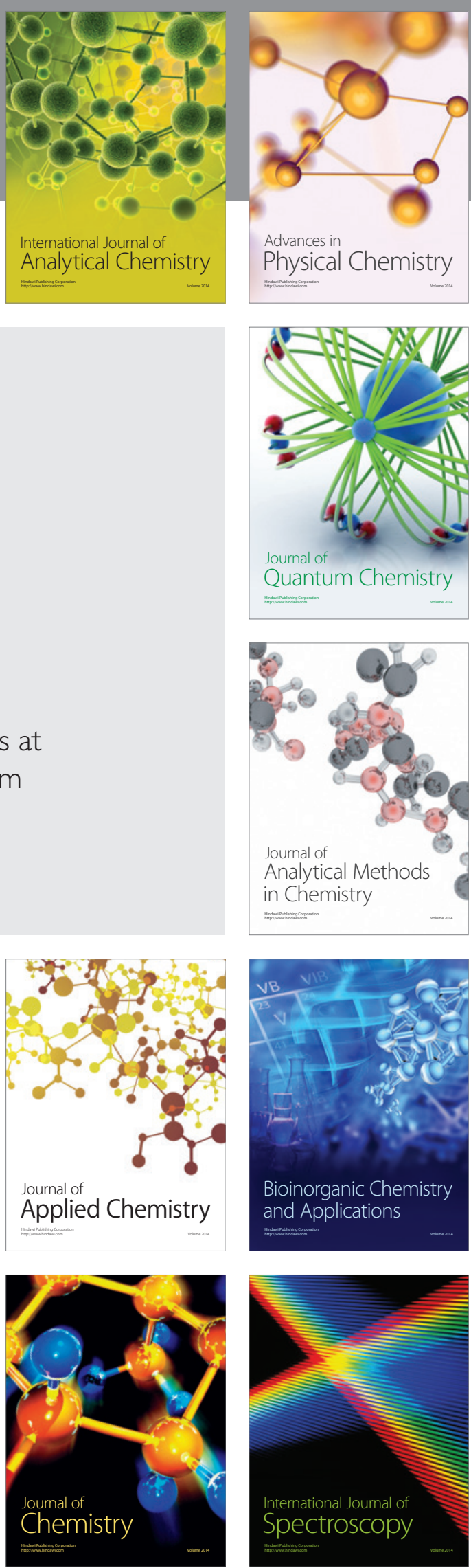